\title{
Co-Creating Value through Agents Interaction within Service Network
}

\author{
Liane Okdinawati(i), Togar M. Simatupang(iD), Yos Sunitiyoso \\ School of Business and Management, Bandung Institute of Technology (Indonesia) \\ aneu.okdinawati@sbm-itb.ac.id, togar@,sbm-itb.ac.id, vos.sunitivoso@sbm-itb.ac.id
}

Received: June 2016

Accepted: February 2017

\section{Abstract:}

Purpose: The purpose of this paper is to give further understanding on value co-creation mechanisms in B-to-B service network by reinforcing the processes, the relationships, and the influences of other agents where Collaborative Transportation Management (CTM) forms might be best employed.

Design/methodology/approach: In order to model the interactions among agents in the collaboration processes and the value co-creation processes, this research used three collaboration cases in Indonesia. The agent-based simulation was used to capture both the collaboration process and the value co-creation process of the three collaboration cases.

Findings: The interactions among the agents both inside and outside their collaboration environments determined agent's role as a value co-creator. The willingness of an agent to accept the opinion of another agent determined the degree of their willingness to co-operate and to change their strategies, and perceptions. Therefore, interaction among agents influenced the size of the value obtained by them in each collaboration process.

Research limitations/implications: The findings of the simulations subject to assumptions based on the collaboration cases. Further research is related to how to encourage agents to co-operate and adjust their perceptions. 
Practical implications: It is crucial for the practitioners to interact with another agent both inside and outside their collaboration environment. The opinions of another agent inside the collaboration environment also need to be considered.

Originality/value: This research is derived from its emphasis on how a value is co-created by reinforcing both the collaborative processes and the interactions among agents as well as on how CTM might be best employed.

Keywords: value co-creation, collaboration, transportation services, interaction, agent-based modelling, service network

\section{Introduction}

One of the challenges in today's business environment is to create value for customers. This has become the idea behind the Service-Dominant (S-D) Logic, where all agents in a business environment are concerned with the exchange of service by using resources, knowledge, and skills for the benefit of consumers (Vargo \& Lusch, 2011). The main challenge for a company is to develop its business strategy based on S-D logic in order to create a value when the value co-creation emerges from the interaction of many parties and the complex configurations of resources and information within companies and across companies (Maglio \& Spohrer, 2013). Therefore, collaboration strategies are required as business strategy to create a value.

In this research, a collaboration in transportation area was used to increase an understanding on how to increase service provision in a service network, where service providers and service clients act together to co-create a value in complex value networks. Collaboration in transportation area, known as Collaborative Transportation Management (CTM), adds a value to a collaborative relationship and an entire collaboration process, by using information sharing to support decision makers in strategic collaborative logistics, transport design, and planning. (Gonzalez-Feliu, Morana, Grau \& Ma, 2013). Esper and Williams (2003) and Bishop (2004) state the needs to incorporate CTM into logistics to avoid logistics bottlenecks, reduce inefficiency, and provide mutual benefits for all collaborative parties.

The research on value co-creation where the value created in both the networks and the interactions among agents in the service network seemed to be ignored (Ramirez, 1999). Particularly, in the transportation area, most of the previous researchers focus on value co-creation models for public transportation, on CTM models for different issues, and on the efficiency and outcome of the 
operational processes in the transportation area (Okdinawati, Simatupang \& Sunitiyoso, 2015). This might have been caused by the fact that the complexities and dynamics of a collaborative transportation service network that include different objectives, perspectives, roles, and responsibilities among agents in collaboration processes. Therefore, value networks, value co-creation processes, and interaction among different agents in the transportation area need to be modeled.

A value is created collaboratively in interactive configurations when all social and economic actors engaged in mutual exchange (Vargo \& Lusch, 2011). Interactions among agents not only enhance the development of mutual relationships among agents in a supply chain but also increases the opportunities to deliver a value for their customers through actions that influence the other agent's process (Grönroos \& Ravald, 2011). They also state that value co-creation for the customer is created throughout the interactions and relationships between the customer and business parties. According to Kanter (2008), there are three fundamental aspects of the business relationship: mutual benefits for all agents; a collaboration to create value; and a close relationship among agents. Therefore, all agents in CTM have to share their information through interactions and close relationships, to create services together, and to learn from one another in order to co-create a value.

In order to simulate the interactions among agents in this research, the agent-based model was used based on the consideration that the agent-based model captures the interaction among agents and learning processes in CTM. Gilbert (2010) states that the agent-based model consist of agents that interact within an environment where they can interact and pass information to one another as well as use the information for the learning process. Therefore, the agent-based model is considered appropriate to model the behaviors of the agents in CTM, which leads to co-create a value.

The purpose of this research is to increase an understanding of value co-creation in the transportation service network through the interactions, close relationships among agents, and influences of other agents. This research addresses on how interactions among agents influence the relationships and learning processes of value co-creation in CTM in order to achieve a mutual value. By using the agent-based model, this research has provided empirical findings that present evidence on the interactions among agents, on the value co-creation process, and on the collaborative process.

The rest of this paper is organised as follows. The related literatures are reviewed in the next section. Then, the interactions among agents in both a collaborative process and a value co-creation process based on the collaboration cases are explained. Next, the simulation processes is explained in section 4. Furthermore, the discussion of the simulation results is presented in section 5. Finally, the conclusions are given. 


\section{Theoretical Background}

\subsection{Value Co-Creation}

A value is created when a customer is satisfied with the product or service that is given by a company, and at the same time, the cross-functional involvement when value co-created was a key driver of revenue generated for the company (Lambert \& Enz, 2012). The term of value in businesses has two approaches: the goods-centered approach and service-centered approach. The objective of the gooddominant (G-D) logic is to create and deliver products to be sold to the customer (Sebastiani, Corsaro \& Vargo, 2014). Therefore, a value is embedded into products and signified by the price of the products or based on what the customer is willing to pay (Vargo \& Lusch, 2008). While S-D logic focuses on the action and value, as the exchanges of a service, a value is co-created by mutual efforts, interactions, and experiences by all business parties and the customer (Vargo \& Lusch, 2011; Prahalad \& Ramaswamy, 2004). A value in S-D logic is defined as the value-in-use, which is created by the customer based on their accumulated experiences that are combined with resources, processes, and outcomes (Voima, Heinonen \& Strandvik, 2010).

Value co-creation is created through interactions and close relationships between business parties and their customers (Grönroos \& Ravald, 2011). Storbacka, Frow, Nenonen and Payne (2012) also mention that a value co-creation process is performed by using information, knowledge, skills, and other competencies of all business parties to achieve a particular goal. Based on that, the term of value co-creation is related to the interactions, the integration of recourses, and exchanges between all parties in a business network. In this research, the value co-creation in CTM is defined as a value that is co-created by agents in every stage of a collaboration, where the agents exchange information and competences in order to achieve a value for themselves, for other agents, and eventually for the customer throughout an on-going process.

\subsection{Collaborative Transportation Management (CTM)}

CTM is defined as a transportation process, which is based on the interactions, coordination, and collaborations among the shippers, receivers, and transportation service providers involved in the logistics process (Okdinawati et al., 2015). In this research, the collaboration in the transportation area is classified as the collaboration strategies in the service network. This type of collaboration is used after the order generated via the Collaboration Planning Forecasting Replenishment (CPFR) was executed (VICS, 2004). Previous researchers showed that CTM reduced transportation costs, 
travelling time, inefficiency, and $\mathrm{CO}_{2}$, increased responsiveness (Esper \& Williams, 2003; Sutherland, 2003; Bishop, 2004; VICS, 2004; Gonzalez-Feliu et al., 2013).

VICS (2004) developed CTM because several activities were not included in the CPFR, such as shipment assignments, carrier assignments, scheduling, and tracks and traces. VICS (2004) defines CTM as a holistic process that brings together all parties in the supply chain, especially shippers, receivers, and carriers to reduce inefficiencies and to improve performances of all parties involved through a collaboration in the transportation planning and execution process. CTM has been used in different types of collaboration to create the optimal scenarios for the collaborative parties in different planning levels. There are three planning level used by VICS (2004), i.e. the strategic level (the first level), the tactical level (the second level), and the operational level (the last level).

\section{Interaction Models}

In order to model the interactions among agents in both the collaboration processes and the value co-creation processes, this research used three collaboration cases in Indonesia. Six informants, as the representatives of each company in the collaboration cases, were interviewed for 2-3 hours in 4 different sessions. Other sources of data collection were also used, such as contract documents, company records, and reports. The selection of the collaboration cases, based on the recommendations of practitioners and academics, was determined on the bases of the degree of the collaboration maturity and involvement of each agent in the collaborative processes.

The first collaboration case is the collaboration between Lookman Djaja and Enseval. Enseval is one of the largest pharmaceutical distributors in Indonesia (The Jakarta Post, 2011) and has 40 branches across Indonesia. Enseval has a role both as the shipper and as the receiver in CTM to dispatch supplies within 24 hours to hospitals, clinics, and outlets. Lookman Djaja, as a carrier, was considered as the best vendor by Enseval in the year 2014. Lookman Djaja owned 280 trucks distributing healthcare products from the Enseval Regional Distribution Centre in Jakarta to the Enseval Distribution Centre in Surabaya.

The second collaboration case is the collaboration between Iron Bird and 7-Eleven. 7-Eleven, as a convenience store, has a role as the shipper and the receiver in CTM. 7-Eleven is becoming an Indonesia's trendy hangout because 7-Eleven blends its small supermarkets with its food and beverage retailers and provides sidewalk seating (Deutsch, 2011). In Indonesia, 7-Eleven began with 20 stores in 2010 and increased to 186 stores in 2015. Iron Bird, as the carrier, is a subsidiary of Blue Bird Group, which is one of Indonesia’s biggest taxi operators (Hutton, 2015). Iron Bird distributes 
products from the 7-Eleven Central Distribution Centre to all 7-Eleven stores in Jakarta. There are two types of services given by Iron Bird to 7-Eleven. The first service is dedicated services, tailor-made services, which is adapted specifically for 7-Eleven. The second service is on call service, designed to give transportation services outside the scheduled services.

The third collaboration case is the collaboration between Inprase and Indorama Ventures Indonesia (IVI). IVI is known as the world's largest producer of polyester, synthetic rubber gloves, and resins (Karmali, 2014). Inprase, as the carrier, owns 350 trucks that distribute IVI's raw materials from Merak to Tanggerang. The main business specialty of Inprase is to distribute oil, natural gas, and chemical goods.

\subsection{Collaboration Process}

The collaboration process for CTM was developed in six stages. It was developed to capture the interactions, actions, and the effects of a decision-making for the vertical collaboration in business processes. The collaboration stages were adopted from Dwyer, Schurr and Oh (1987). The first stage is the formation stage. In this stage each agent is considered feasible as a collaborative partner and is only limited to enhance one another's attractiveness to join collaboration. Revealing the specific information among agents is used to position their own attractiveness to join collaboration.

The second stage is the preparation stage. In the preparation stage, each agent's interests, obligations, benefits, and burdens are explored. In this stage, all agents align their perceptions based on each agent's strategic structure formation, communication, and power structure. The third stage is the design stage. In this stage, each agent agrees on its own roles and responsibilities as part of collaborative arrangements, which is based on several considerations such as incentive alignment, information structure, performance metrics, and process integration.

The fourth stage is the planning stage where a hierarchical decision-making is developed on the strategic, tactical, and operational level to give reassurance that each agent will collaborate in accordance with the agreement. The decision made in this stage is used as the blueprint for the implementation stage. The fifth stage is the implementation stage. This stage occurs when all agents have performed the hierarchical decision-making in the planning stage on a daily basis to achieve the objectives of the strategic, tactical, and operational level. The repeated change of information structure, performance metrics, and process integration in the design stage may occur in order to increase services. The last stage is the evaluation stage, where the evaluation of a collaboration process is done, and whose results are used as the input for the agents to determine whether to 
modify or to terminate the agreement they have made. The results of the evaluation stage are also used to measure the economic impacts and the outcomes of CTM.

\subsection{Value Co-Creation Process}

In order to model the interactions of agents in value co-creation, the five value in CTM are used. Those values are developed based on the objectives of the customers and all agents involved in CTM. Sutherland (2003) state that value in CTM may include improving the transportation's components of the supply chain, eliminating inefficiencies, reducing costs, and ensuring reliability in the movement of goods. The five value in CTM are as follows:

(1) Information value (Allee, Schwabe \& Babb, 2015; Graves, 2010) refers to information that can be drawn on by agents in order for them to function effectively in CTM.

(2) Relationship value (Smith \& Colgate, 2007; Sanders \& Simons, 2009; O’Cass \& Ngo, 2011; Ritter \& Walter, 2012) is the way in which agents and their customers regard and behave toward each other in a collaborative process.

(3) Quality value (O’Cass \& Ngo, 2011) as the value of service performance, includes durability, reliability, etc. of that service.

(4) Time value (Smith \& Colgate, 2007) refers to the measured or measurable period during which an action, process, or condition exists.

(5) Monetary value (Sanders \& Simons, 2009; O’Cass \& Ngo, 2011; Smith \& Colgate, 2007; Allee et al., 2015) relates to economic aspects such as cost and price of a service in exchange for the service.

Value co-creation happens in CTM when agents interact with one another in an activity in all stages of the collaborative process. The value co-creation can be seen in Table 1 when both the activities of one agent and the value created by one agent's activities influence the other agents' activities. In order to co-create a value, this interactions and relationships in all agents' activities and in their joint activities in CTM must take place. 


\begin{tabular}{|c|c|c|c|c|}
\hline $\begin{array}{l}\text { Collaboration } \\
\text { Stage }\end{array}$ & $\begin{array}{l}\text { Shipper And Receiver } \\
\text { Activities }\end{array}$ & Carrier Activities & Joint Activities & Value \\
\hline Forming & $\begin{array}{l}\text { Revealing information } \\
\text { of desire service } \\
\text { criteria's }\end{array}$ & $\begin{array}{l}\text { Revealing information } \\
\text { of their service }\end{array}$ & Entering tender process & Information \\
\hline \multirow[b]{2}{*}{ Preparation } & $\begin{array}{l}\text { Revealing interests, } \\
\text { objectives, burdens, } \\
\text { expectations of services }\end{array}$ & $\begin{array}{l}\text { Revealing interests, } \\
\text { objectives, burdens, } \\
\text { services specification, } \\
\text { and quality }\end{array}$ & $\begin{array}{l}\text { Knowing interest, objective, } \\
\text { burdens, services specification, } \\
\text { skills \& capabilities }\end{array}$ & Information \\
\hline & \multicolumn{2}{|c|}{$\begin{array}{l}\text { Making decision based on preferences \& objectives } \\
\text { in strategic, tactical, \& operational level }\end{array}$} & $\begin{array}{l}\text { Aligning difference interests, } \\
\text { objectives, burdens, } \\
\text { expectations, and proposes of } \\
\text { service specification, } \\
\text { performance \& quality }\end{array}$ & Relationship \\
\hline \multirow[t]{2}{*}{ Design } & \multicolumn{2}{|c|}{$\begin{array}{l}\text { Revealing information based on aligning } \\
\text { preferences. This include revealing information of } \\
\text { service specifications, performance, and skills }\end{array}$} & $\begin{array}{l}\text { Deciding incentive alignment, } \\
\text { performance metrics, business } \\
\text { processes, information structure }\end{array}$ & Information \\
\hline & \multicolumn{2}{|c|}{ Adjusting services, processes, resources, etc. } & $\begin{array}{l}\text { Deciding to conduct pilot } \\
\text { project }\end{array}$ & Quality \\
\hline \multirow{4}{*}{ Planning } & \multirow{4}{*}{$\begin{array}{l}\text { Revealing information: } \\
\text { production volume, } \\
\text { location, and time }\end{array}$} & \multirow{4}{*}{$\begin{array}{l}\text { Revealing information: } \\
\text { transportation resources } \\
\text { and capacity }\end{array}$} & Making agreement & Information \\
\hline & & & $\begin{array}{l}\text { Determining order/production } \\
\text { configuration \& location }\end{array}$ & \multirow[t]{2}{*}{ Quality, Time } \\
\hline & & & Establishing order shipment & \\
\hline & & & $\begin{array}{l}\text { Determining information } \\
\text { needed to be shared }\end{array}$ & Information \\
\hline \multirow{2}{*}{ Implementation } & $\begin{array}{l}\text { Revealing information: } \\
\text { production, time, } \\
\text { performance metrics }\end{array}$ & $\begin{array}{l}\text { Revealing information: } \\
\text { assignment, } \\
\text { transportation resources, } \\
\text { routing, and scheduling }\end{array}$ & $\begin{array}{l}\text { Day to day operation by making } \\
\text { delivery status, receive status, } \\
\text { documentation }\end{array}$ & \multirow{2}{*}{$\begin{array}{l}\text { Quality, } \\
\text { Time, } \\
\text { Monetary }\end{array}$} \\
\hline & $\begin{array}{l}\text { Day to day operation by } \\
\text { determining order } \\
\text { shipment }\end{array}$ & $\begin{array}{l}\text { Service in accordance } \\
\text { with shipper \& receiver } \\
\text { expectation, and carrier } \\
\text { skill \& capabilities }\end{array}$ & $\begin{array}{l}\text { Preparing continuous } \\
\text { improvement in the future }\end{array}$ & \\
\hline \multirow{4}{*}{ Evaluation } & \multicolumn{2}{|c|}{$\begin{array}{l}\text { Revealing information related to day to day } \\
\text { performance }\end{array}$} & \multirow{4}{*}{$\begin{array}{l}\text { Evaluating performance metrics } \\
\text { scorecards }\end{array}$} & \multirow{4}{*}{$\begin{array}{l}\text { Information, } \\
\text { Quality, Time }\end{array}$} \\
\hline & \multicolumn{2}{|c|}{ Calculating Performance metrics scorecards } & & \\
\hline & \multicolumn{2}{|l|}{ Doing Risk analysis } & & \\
\hline & \multicolumn{2}{|l|}{ Benchmarking (optional) } & & \\
\hline
\end{tabular}

Table 1. Value Co-creation and Activities of Agents 


\section{Simulation Process}

Both the collaboration process and the value co-creation process in this research are developed based on the three collaboration cases. They have provided insights on the application of the multi-agent model in the real system. Each agent has a different role, perspective, and objective when joining the collaboration. There are three different strategies used in the collaborative process of the three cases. In this research, those strategies are simulated in three different scenarios from which the agents can choose. The first scenario is used when all agents interact with one another only inside their collaboration environment. The second scenario is used when all agents interact with one another in their collaboration environment and also interacts with one another outside their collaboration environment. All agents interact with one another outside their collaboration environment for benchmarking purposes. The third scenario is used when agents interact with one another both inside and outside their collaboration environment, and also when they use their opinion value inside their collaboration environment.

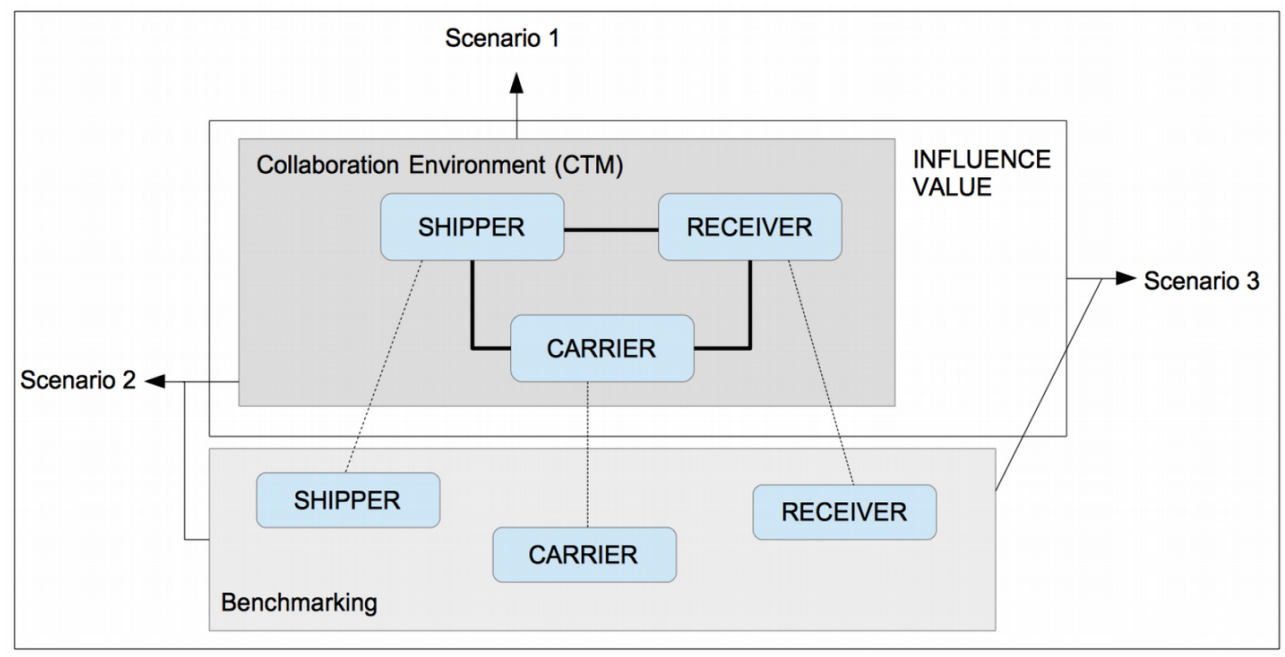

Figure 1. Simulation Scenario

In each scenario, each agent can choose 6 actions based on the degree of the maturity model. The maturity model represents the degree of integration process in the supply chain (Lockamy \& McCormack, 2004). The first action can be chosen to end the collaboration process if the agents have nothing in common on their perspectives and objectives, or if the agent cannot align their perspectives and objectives. The second action can be chosen when all of the agents decide to continue the collaboration process. However, since the service characteristics and performance structures are poorly defined and unpredictable, this action will likely cause all of the agents to co-create a low value. The third action is chosen when all of the agents agree to structure the basic collaboration process and start to 
define the required information properly. In this action, the levels of value co-creations improve, but they still remain low if compared to other actions.

The fourth action can be selected when all of the agents agree to cooperate with one another. The pilot project proposed in this action is to gain better service performances. The efforts for continuous improvement are made only by the carrier to achieve better service performances. The agents can choose the fifth action where performance metrics are used as the basis for decision making in the collaborative process. All of the agents conduct the process of improvements. Therefore, the costs are drastically reduced, and the value are increased gradually. The agents choose action six when the value co-creation process is developed throughout the collaboration process. All of the agents conduct the improvements in all aspects of the collaborative process. The benefits are shared among the agents, and the value are measured against the expanded objectives throughout the collaboration process. The interactions, roles, and rules of each agent in CTM in the six collaboration stages are illustrated in Figure 2. 


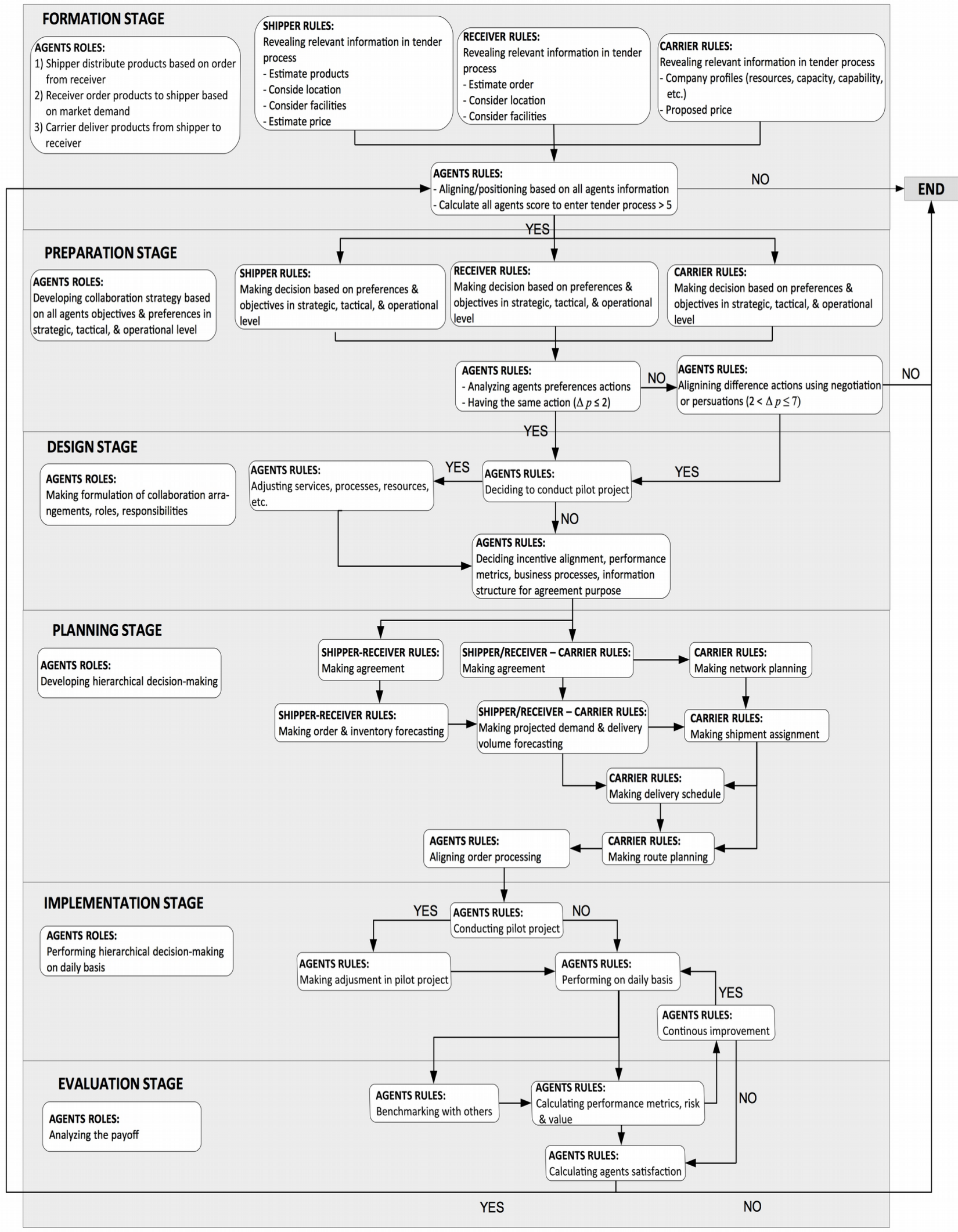

Figure 2. Rules and Roles Agents 
Each agent has its own criteria for the components of a value, and each criterion has randomly been generated by computers at the initialization of the simulation process. Each agent also has its own perspectives based on the components of the value. SOARS is used for the simulation of agent-based model in this research. The simulation process runs for 15 iterations, representing years and for 50 times. Q-learning algorithm is also used to model how the agents in CTM learn and adapt to choose the actions based on trial and error in each collaboration stage in order to co-create a value. In addition, the Q-learning algorithm is used to calculate the value captures of the agents in CTM in each collaboration stage. Therefore, in this algorithm, the agents in the environment learn to choose the actions based on trial and error, which give higher value than the previously selected actions (Watkins \& Dayan, 1992; Pandey, Khumar \& Pandey, 2010). The Q-learning function (Watkins \& Dayan, 1992) is defined as follows:

$$
Q_{t+1}\left(s_{t}, a_{t}\right)=Q_{t}\left(s_{t}, a_{t}\right)+\alpha_{t}\left(s_{t}, a_{t}\right)\left(R_{t+1}+\gamma \max Q_{1}\left(s_{t+1}, a\right)-Q_{t}\left(s_{t}, a\right)\right)
$$

Where: $Q_{t+1}\left(s_{t}, a_{t}\right)=$ new value,

$a_{t}=$ learning rate,

$R_{\iota+1}=$ reward,

$\gamma=$ discount factor,

$\max Q_{t}\left(s_{t+1}, a\right)=$ estimate of optimal future value,

$Q_{t}\left(s_{t}, a_{t}\right)=$ old value.

Learning rate $(0<a \leq 1)$ represents the extent of the new information that substitutes the old information. 0 learning rate represents that the agent in the model does not learn anything, and 1 represents that the agent in the model considers only the most recent information. Discount factor determines the importance of the future value for the agent in the model. 0 represents that the agent only focuses on the current value, and 1 represents a long-term high value. In this research, although $a_{t}$ decreases from 1 to almost 0 ( $a_{t}=1$ /iteration), it is regarded as a learning rate with the consideration that by using this learning rate all of the agents detect and absorb not only new information. For the discount factor, $\gamma=$ iteration/ iteration, it is used based on the consideration that all of the agents focus on the long-term reward, which is to co-create a value.

Value function that is adopted from Stewart and Ebrary (2010) is also used to define the value co-creations of all of the agents in CTM. The value function is expressed as follows:

$$
V \text { alue }=\frac{\text { Information }+ \text { Relationship }+ \text { Quality }}{\text { Time }+ \text { Monetary }}
$$


In order to co-create a value, two types of learning are used, i.e. individual learning and coordination learning. Individual learning is used when an agent learns its own strategies independently, while coordination learning is used when the agents need to coordinate their actions to jointly create a value. These two types of learning are used based on the consideration that in the first stage, which is the formation stage, all of the agents interact with one another using its own information and choosing the actions individually. For the other stages, coordination learning is used to coordinate the agents' actions in the collaborative processes. When an agent use coordination learning, it learns a joint action based on the information shared by all agents.

Reinforcement learning is used in this research with the purpose of allowing each agent to explore its own environment in order to maximize a value. Therefore, Boltzmann exploration is used as the exploration technique where each agent chooses the actions by exploring its own environment based on the probability. Boltzmann's distribution is expressed as follows:

$$
\frac{e^{Q(s, a) / T}}{\sum_{a^{\prime} \in A} e^{Q\left(s, a^{\prime}\right) / T}}
$$

Where $Q(s, a)$ is the agent's estimate of the $Q$-value of performing action $a$ at state $s$.

For scenario 3, when the agents interact with one another in both inside and outside their collaboration environment, not only do they communicate with one another, but also their actions can influence the other agents' behaviors. This approach is based on Influence Value Reinforcement Learning (IVRL), where agents calculate the value of their actions based on the influence rates and the opinions of the other agents that relate to the executed actions (Barrios-Aranibar \& Gonçalves, 2009). The IVRL is defined as the Equation (4).

$$
I V_{i}=\sum_{j=1}^{i=1} \beta_{i}(j) * O P_{j}(i)+\sum_{j=i+1}^{N} \beta_{i}(j) * O P_{j}(i)
$$

Where: $\beta_{i}(\gamma)=$ the influence rate of the agent $j$ over $i$.

$O P_{j}(\imath)=$ the opinion of agent $j$ in relation to action executed by the agent $i$.

$$
\begin{gathered}
O P_{j}(i)=R V_{j} * P e\left(s(t), a_{i}(t)\right) \quad \text { if } \quad R V_{j}<0 \\
O P_{j}(i)=R V_{j} *\left(1-P e\left(s(t), a_{i}(t)\right)\right) \text { if } R V_{j}>0 \\
R V_{j}=r_{j}+\max _{a_{j} \in A_{j}} Q\left(s(t+1), a_{j}\right)-Q\left(s(t), a_{j}(t)\right)
\end{gathered}
$$


Where: $\operatorname{Pe}\left(s(t), a_{i}(t)\right)=$ the occurrence index (times action $a_{i}$ is executed by the agent $i$ in state $s(t)$ over times the agent $i$ has been in state $s(t))$,

$Q\left(s(t), a_{j}\right)=$ the value of the state-action pair of the agent $j$ at time $t$,

$A_{j}=$ the set of all agents' action $j$ can be executed.

Influence rate $(0 \leq \beta \leq 1)$ represents that an agent either is or is not influenced by the opinions of the other agents. Opinion value is described as the value of an agent that is related to the actions of the other agents. Based on IVRL, if the reward of the action chosen by an agent is greater than the value of its own action, the opinions about the action, performed by the other agents, are positive. Furthermore, if the reward of the action chosen by an agent is lesser than the value of its own action, the opinions related to the action, made by the other agents, are negative. It indicates that when an agent has a positive opinion of the other agents' actions, the other agents will eventually repeat the same actions and will eventually avoid the actions that cause negative opinions.

There are two stages of validation process in this research. The first validation was done when the interaction models developed both the collaboration processes and the value co-creation processes. The second validation was done to validate the simulation results. Face validation was used for both stages, where both the experts and the practitioners were asked to make a judgment if the interaction models and the simulation results had a similar pattern with the real system and achieved the intended purposes.

\section{Simulation Results and Discussion}

The agent-based simulation was used to capture both the collaboration process and the value co-creation process of the three collaboration cases. The three scenarios were used to capture the best strategies that can be chosen by the agents and also capture the interactions among the three different agents such as a shipper, a receiver, and a carrier in each scenario. In the first scenario, the agents only interacted and learned from one another in their collaboration environment. In the second scenario, all agents not only learned from one another in their environments, but they also learned through social interactions. Social interaction in this research is assumed to happen when an agent conducted a benchmarking with other agents outside their collaboration environment. In the third scenario, the three agents in CTM interacted and learned from one another inside and outside their environment through social interactions, and were influenced by the opinions of the other agents. The main objectives of the simulation are to observe in which scenario an agent is able to learn and co-create the highest value in CTM. 
In the first stage, which is the formation stage, an agent learned independently to continue the collaboration process to achieve a better value. In scenario 3, the agents had the probability of $100 \%$ to learn to choose action 6 in 6 years. In scenario 2, all agents also had the probability of 100\% to choose action 6 in 6 years. However, in scenario 1, all agents only had 100\% probability to learn to choose the action 6 in 10 years. At this stage, the information value is obtained by the agents individually. For all agents, the highest information value obtained in scenario 3 was at the end of iteration. This occurred because the agents in scenario 1 only had limited information to choose an action to obtain a maximum information value. Information value of the agents can be seen in Figure 3.

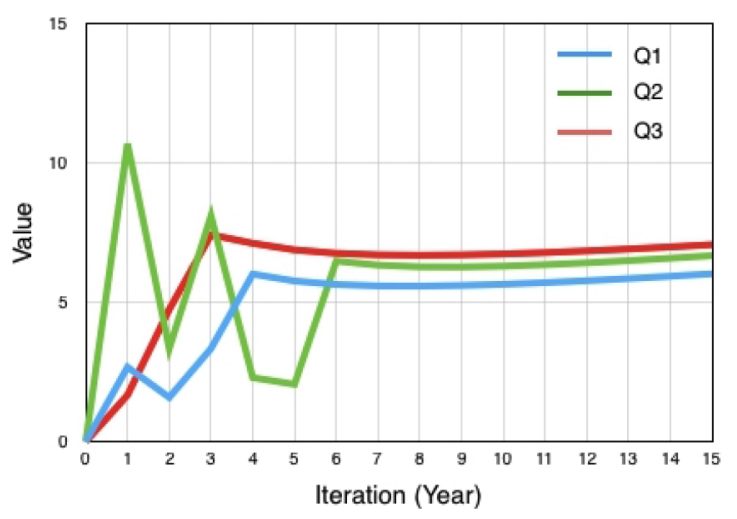

(a) Information Value for Shipper

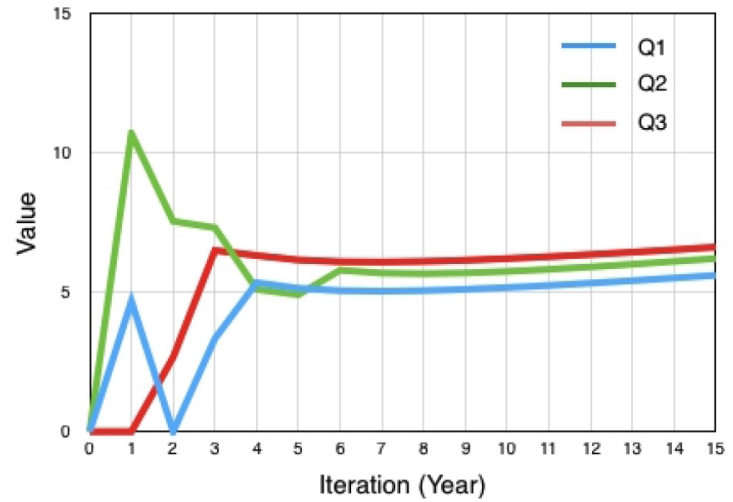

(b) Information Value for Receiver

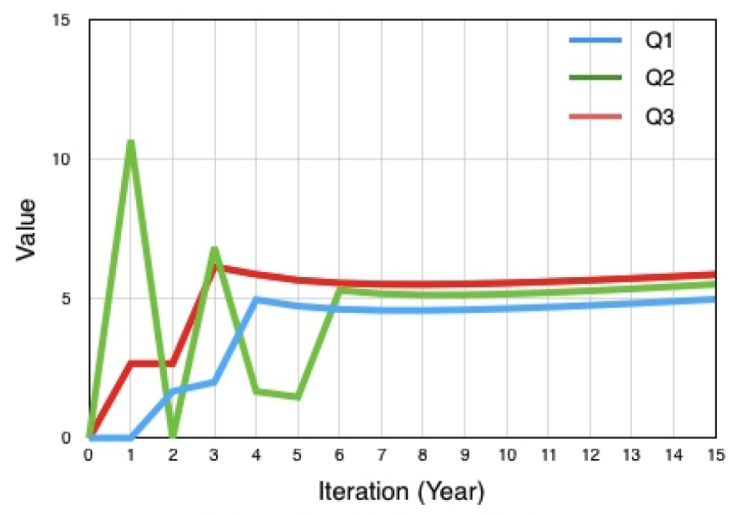

(c) Information Value for Carrier

Figure 3. Information Value of the Agents in Formation Stage: (a) Shipper, (b) Receiver, and (c) Carrier

In the preparation stage, coordination learning was used by jointly coordinate all of the agents' actions. Therefore, the agents were able to generate the same value range. In scenario 1, all of the agents only generated 12.93 for the information value and 8.711 for the relationship value. In scenario 2, all of the agents generated 14.068 for the information value and 9.211 for the relationship value. On the other hand, in scenario 3, all of the agents generated 15.624 for the information value and 9.911 for the relationship value. Scenario 3 had the highest information value and relationship value compared to the 
other scenarios. Moreover, since the agents were able to align their preferences and objectives in this stage, the agents were able to accelerate the probability of choosing action 6 . They accelerated the probability to choose action 6 from 10 years to 6 years in scenario 1, from 6 years to 5 years in scenario 2 , and from 6 years to 4 years in scenario 3 . These happened because the influence and opinion of the other agents contributed to one agent's decision to continue, negotiate, or stop the collaboration process. In this research, when one agent chose to negotiate with the other agents, more information would be obtained and so the agent had a better understanding of the other agents' objectives and preferences. The value of information and relationship in the preparation stage can be seen in Figure 4 . Figure 4 shows each time the agents choose to stop the collaboration process, the relationship value declines. Also, each time the agents choose to continue or negotiate with the other agents, the relationship value increases.

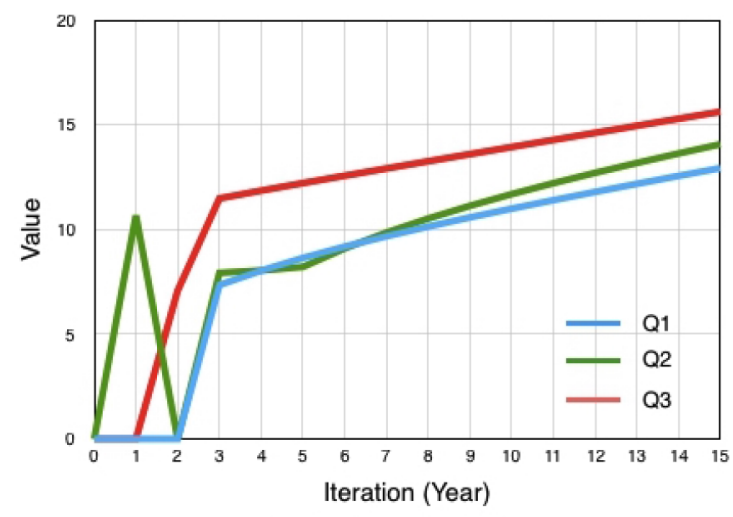

(a) Information Value

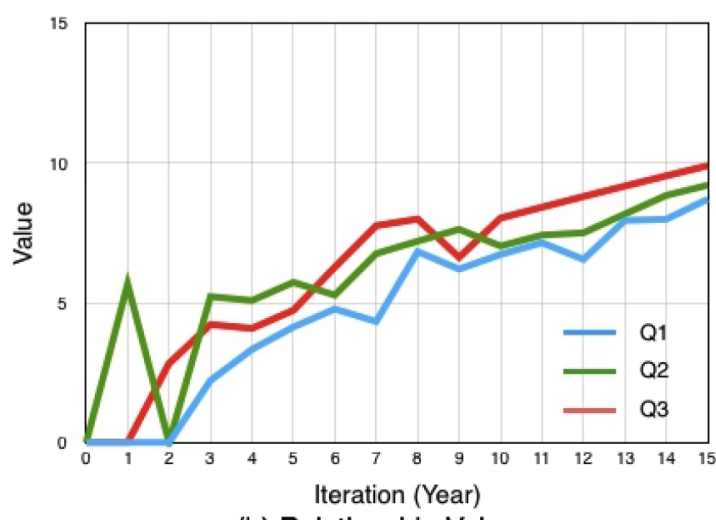

(b) Relationship Value

Figure 4. Value Generated in Preparation Stage: (a) Information Value, (b) Relationship Value

In the third stage, the design stage, where the strategy decision at this stage was based on the choice of action and on the state of information in the previous stage, the decision affected the value obtained by the agents. Scenario 3 had the highest information value and quality value compared to the other scenarios. In scenario 1, all of the agents obtained 13.188 for the information value and 11.787 for the quality value. In scenario 2, all of the agents generated 14.547 for their information value and 16.089 for their quality value. In scenario 3, all agents generated 15.969 for their information value and 16.902 for their quality value in 15 iterations. The influence of the opinion of the other agents were not only used to align their actions and objectives but also were used to adjust their services and processes by adjusting their incentive alignments, performance metrics, business processes, and information structures. The simulation results of the design stage can be seen in Figure 5. 


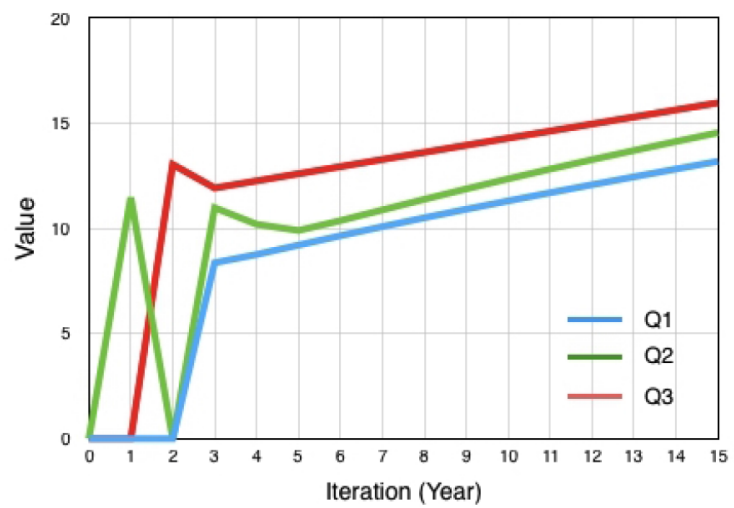

(a) Information Value

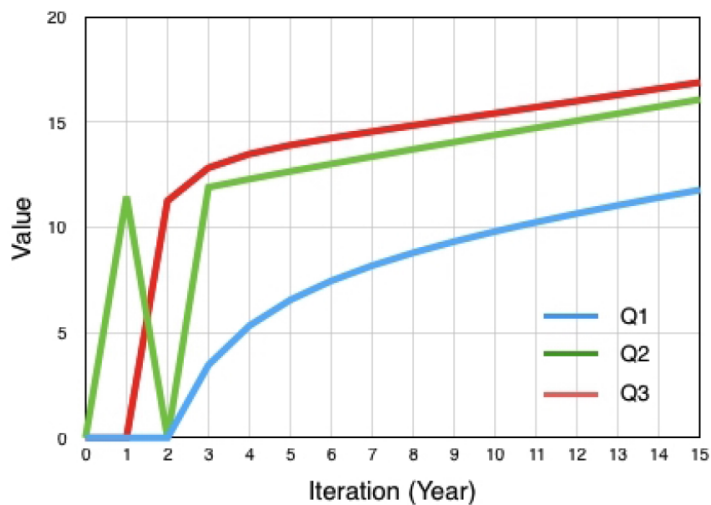

(b) Quality Value

Figure 5. Value Generated in Design Stage: (a) Information Value, (b) Quality Value

In the planning stage, where the value capture in this stage was derived from a joint action among the agents and was also based on the information from the previous stages, both of the information value and the quality value in scenario 3 was bigger than scenario 1 and 2. Scenario 1 generated 13.509 for the information value and 12.2 for the quality value. Scenario 2 generated 14.734 for the information value and 16.349 for the quality value. Scenario 3 generated 16.034 for the information value and 17.122 for the quality value. Moreover, both the social interaction and the influence of the opinion of an agent caused more information capture related to the best strategy to co-create a value. Furthermore, in order to increase the value co-creation at the end of the collaboration, the time value in scenario 3 must be smaller than scenario 1 and 2. Scenario 1 has the time value 14.711, while the scenario 2 and 3 generated the time value of 14.007 and 11.040, respectively. This happened because the action choices made by the agents in the preparation stage and also were based on the formulation of decision-making structures, information structures, and processes of integration in the design stage. The simulation results for the planning stage can be seen in Figure 6. 


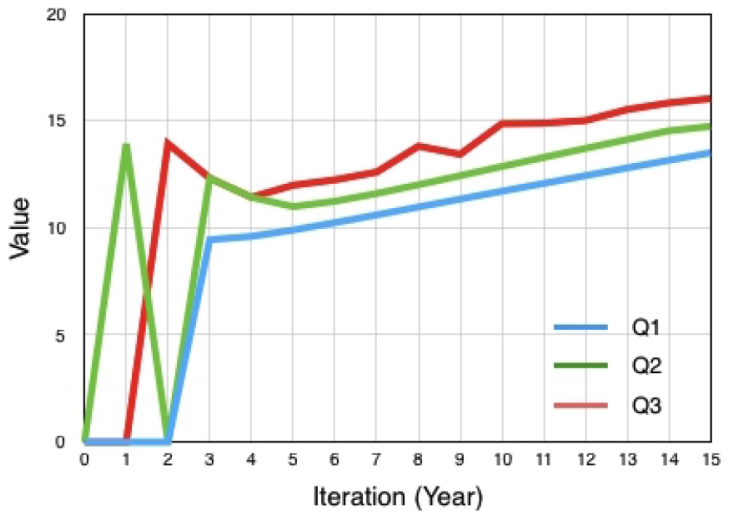

(a) Information Value

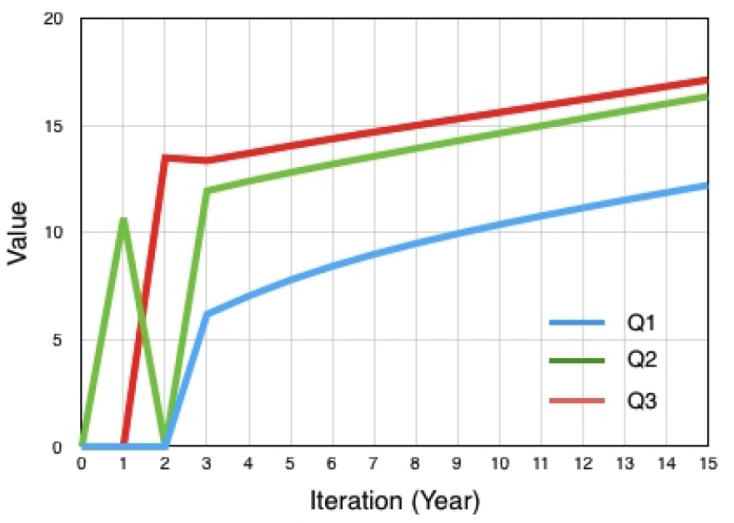

(b) Quality Value

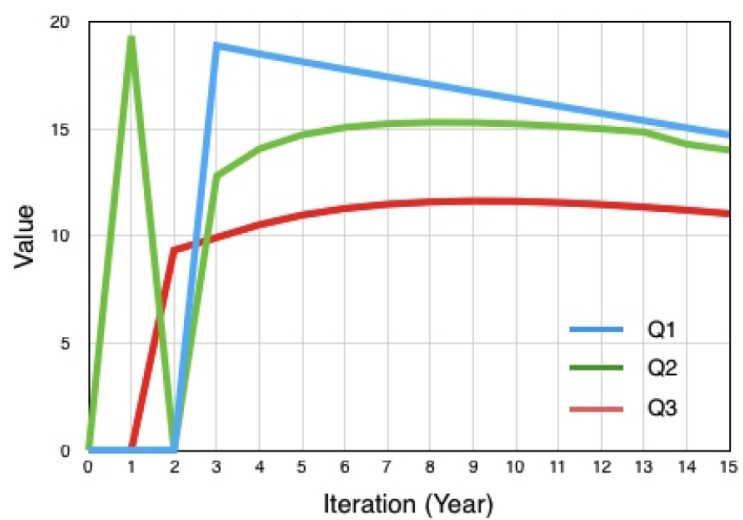

(c) Time Value

Figure 6. Value Generated in Planning Stage: (a) Information Value, (b) Quality Value, and (c) Time Value

In the implementation stage, in scenario 1, all of the agents generated 13.254 for the quality value, 14.697 for the time value, and 17.711 for the monetary value. In scenario 2, all of the agents obtained 17.259 for the quality value, 14.039 for the time value, and 16.467 for the monetary value. In scenario 3 , all of them obtained 18.059 for the quality value, 10.892 for the time value, and 12.206 for the monetary value. This happened, because the agents in scenario 3 had more information resulting from both the social interactions and the influences of the opinions of the other agents. This affected their decision to perform a continuous improvement, which was used as the foundation to learn, to modify, or to adapt their services. Therefore, performing a continuous improvement caused the increase of quality value, but decrease of the time value and the monetary value. Conducted pilot project in this stage improved both their performance efficiency and their value. The three value obtained in the implementation stage can be seen in Figure 7. 


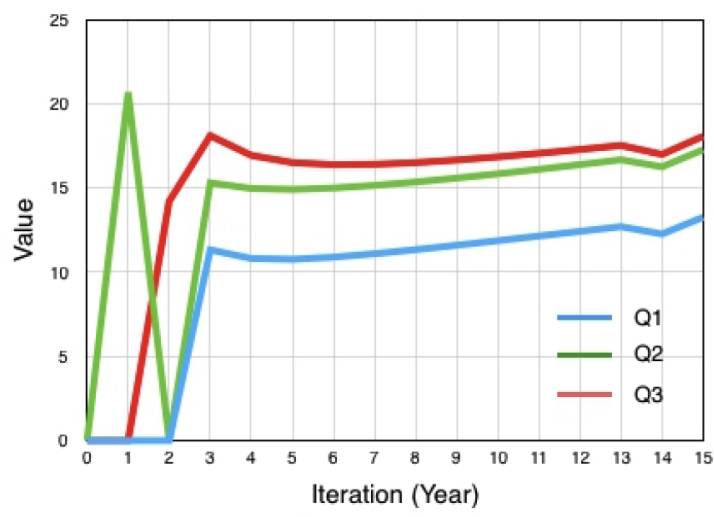

(a) Quality Value

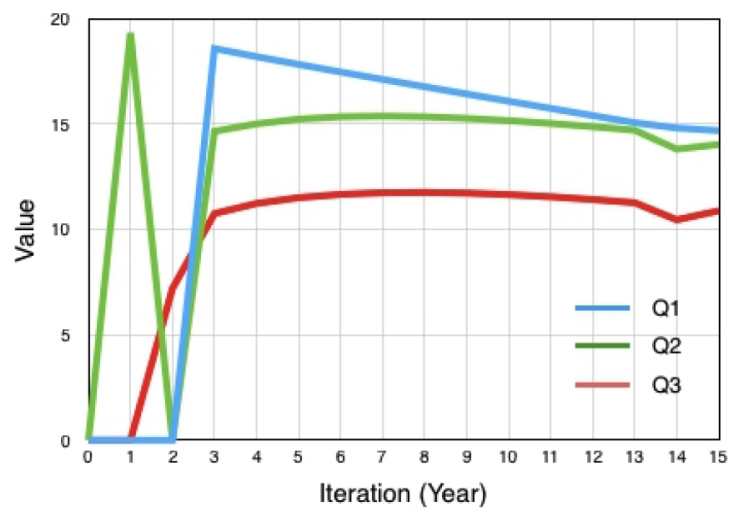

(b) Time Value

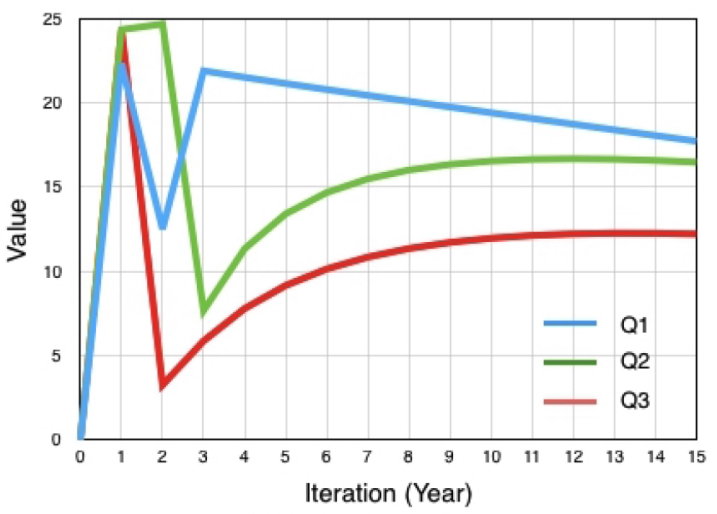

(c) Monetary Value

Figure 7. Value Generated in Implementation Stage: (a) Quality Value, (b) Time Value, and (c) Monetary Value

In the evaluation stage, in scenario 1, all of the agents generated 13.809 for the information value, 13.571 for the quality value, and 14.104 for the time value. In scenario 2 they generated 15.295 for the information value, 17.443 for the quality value, and 13.186 for the time value. In scenario 3 , they generated 16.488 for the information value, 18.198 for the quality value, and 10.747 for the time value. The decision to perform a continuous improvement in the implementation stage influenced both the quality value and the time value obtained in this stage. Their action choices in the preparation stage influenced the formulations of strategies in the design stage, planning stage, and implementation stage. Therefore, both the increased and the decreased value in this stage were resulted from both the action choices and the formulations of strategies in the previous stage. The simulation results for this stage can be seen in Figure 8. 


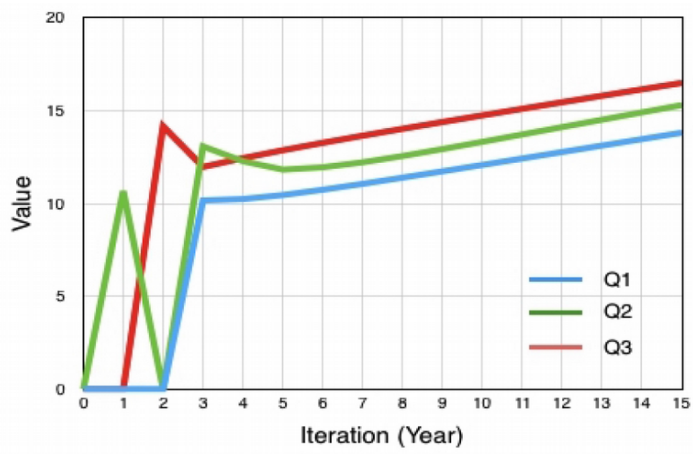

(a) Information Value

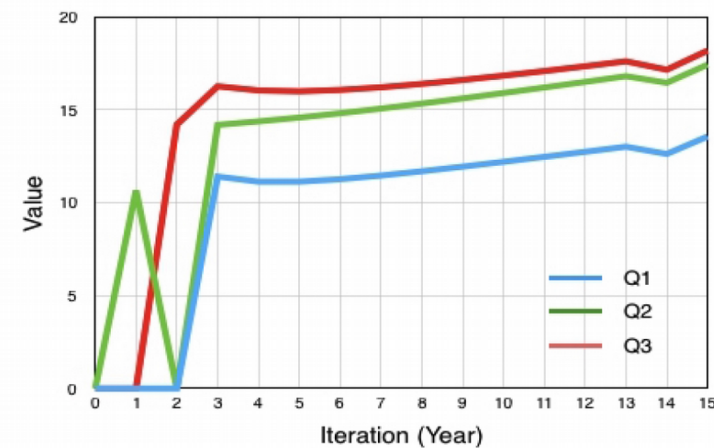

(b) Quality Value

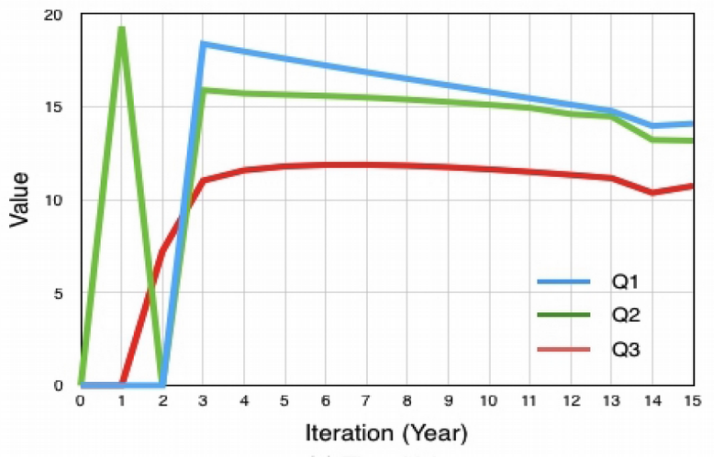

(c) Time Value

Figure 8. Value Generated in Evaluation Stage: (a) Information Value, (b) Quality Value, and (c) Time Value

The value co-creation obtained in this research was calculated by the formulation (2). The value co-creation in scenario 3 was the biggest compared with the other two scenarios, and it continues to increase. This happened because in scenario 3 more information was procured by all of the agents along with both the interactions in each collaboration stage and the influences of the opinions of the other agents. Moreover, what the agents' chose in the both formation stage and the preparation stage influenced the value co-creation they obtained. In Figure 9, it can be seen that the value co-creation for all of the agents declined because they chose action 1, which ended the collaboration process. Action 1 led not only to the reduction of the information value, relationship value, and quality value but also to the increase both the monetary value and the time value. On the other hand, action 6 not only increased the information value, relationship value, and quality value but also reduced both the monetary value and the time value. In other words, both the action and the formulation strategic choice of the agents influenced the size of the value obtained by them in each collaboration process. 


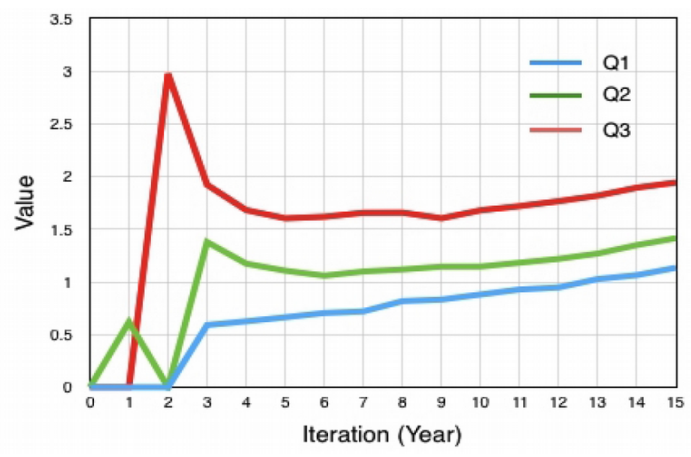

Figure 9. Value Co-creation Obtained by Agents

\section{Conclusions}

Value co-creation is defined as the development of relationships between agents as collaborative partners through ongoing interactions and through systemic, networked, service exchange relationships from all agents involved (Vargo \& Lusch, 2011). The three collaboration cases in this research provided the insight of integrating the value co-creation processes into the collaboration processes among the three agents in CTM: a shipper, a receiver, and a carrier. In this research, the value co-creation is focused on the collaborative process of transportation services. The interactions among the agents as well as the integration of their collaborative processes, learning mechanisms, and the agents' opinions improve the existing services, and the agents' experience.

There are three strategies that were used in the three cases in their collaborative process. As the simulation scenarios show, the agents could choose one of the strategies in this research. The first scenario was used when all of the agents interact with one another only in both the collaboration process and the value cocreation process inside their collaboration environment. The second scenario was used when all of the agents interact with one another in their collaboration environment, and they conducted the social interactions outside their collaboration environment for the benchmarking purpose. The third scenario was used not only when one agent interacted with another agent both inside and outside their collaboration environment but also when one agent used the opinion value of another agent inside its collaboration environment. The simulation results demonstrated that the highest value obtained through interactions among the agents in their collaboration environment and outside their environment was through the benchmarking process. During direct interactions with another agent in their collaboration environment, the influences of the opinions of another agent also resulted in the highest value. This can be seen in the simulation results of scenario 3, where the highest value co-creation was generated, compared to the other scenarios. Based on that, this research indicated that the interactions among the agents both inside their collaboration environment and outside their collaboration environment determined each agent's role, i.e. as a value co-creator. Moreover, the willingness of an agent to accept the 
opinion of another agent determined the degree of their willingness to co-operate and to change their strategies, operation processes, objectives, and perceptions, too.

This research responds to the needs for empirical research on value co-creation mechanisms for B-to-B service network, particularly in the transportation area. Moreover, the novelty of this research is derived from its emphasis on how a value is co-created by reinforcing both the collaborative processes and the interactions among agents as well as on how CTM might be best employed. The contribution of this research for the policy makers is that agents have to learn and adapt in the collaborative process to maximize their benefits of joining the collaborations. For the practitioners in CTM, it is crucial for them to interact with another agent both inside their collaboration environment and outside their collaboration environment. The opinions of another agent inside the collaboration environment also need to be considered to achieve a better customer satisfaction.

However, since the three collaboration cases among the three agents in CTM had brought forth the limitations to generalize the interaction among the agents in the value co-creation process, further research for the value co-creation in the service network, especially in the transportation area, needs to be done in the future. Several interesting aspects to be addressed are (1) how to encourage agents to co-operate and adjust their perceptions and objectives in a value co-creation process, (2) how end customers take a certain role in a service network through direct interactions with all agents in collaborative process, and (3) how the opinions of customers influence the value co-creation process so that the agents adjust their strategic decisions and service development that bring more benefits to the customers.

\section{References}

Allee, V., Schwabe, O., \& Babb, M.K. (2015). Value Networks and the True Nature of Collaboration. Meghan-Kiffer Press.

Barrios-Aranibar, D., \& Gonçalves, L.M. (2009). Influence Value Q-Learning: A Reinforcement Learning Algorithm for Multi Agent Systems. I-Tech, Vienna, Austria. ISBN 978-3-902613-55-4.

Bishop, S.B. (2004). Collaborative Transportation Management Benefits. Supply Chain Systems Inc. Available online at: http://www.vics.org (Accessed: October 2013).

Deutsch, A. (2011). 7-Eleven Becomes Indonesia's Trendy Hangout. Available online at: http://www.ft.com/cms (Accessed: November 2015).

Dwyer, F.R., Schurr, P.H., \& Oh, S. (1987). Developing Buyer-seller relationships. Journal of Marketing, 51, 11-27. 
Esper, T.L., \& Williams, L.R. (2003). The value of Collaborative Transportation Management (CTM): Its Relationship to CPFR and Information Technology. Transportation Journal, 42(4), 55-65. https://doi.org/10.2307/1251126

Gilbert, G.N. (2010). Computational Social Science. London: Sage.

Gonzalez-Feliu, J., Morana, M., Grau, J.M.S., \& Ma, T.Y. (2013). Design and Scenario Assessment for Collaborative Logistics and Freight Transport Systems. International Journal of Transport Economics, 207-240.

Graves, T. (2010). Mapping the enterprise: modelling the enterprise as services with the enterprise canvas. Tetradian Books.

Grönroos, C., \& Ravald, A. (2011). Service as Business Logic: Implications for Value Creation Service as Business. Journal of Service Management, 22(1), 5-22. https://doi.org/10.1108/09564231111106893

Hutton, J. (2015). Indonesia’s Blue Bird Targets New Growth: Noni Purnomo. Forbes Asia. Available online at: http://forbes.com/sites/forbesasia (Accessed: November 2015).

Kanter, R.M. (2008). Collaborative Advantage: The Art of Alliances. Harvard Business Review, 72(4), 96108.

Karmali, N. (2014). Indorama's Amit Loha is the Prince of Polyester. Forbes Asia. Available online at: http://forbes.com/sites/forbesasia (Accessed: November 2015)..

Lambert, D.M., \& Enz, M.G. (2012). Managing and Measuring Value Co-Creation in Business-to-Business Relationships. Journal of Marketing Management, 28(13-14), 1588-1625. https://doi.org/10.1080/0267257X.2012.736877

Lockamy III, A., \& McCormack, K. (2004). Linking SCOR Planning Practices to Supply Chain Performance: An Exploratory Study. International Journal of Operations \& Production Management, 24(12), 1192-1218. https://doi.org/10.1108/01443570410569010

Maglio, P.P., \& Spohrer, J. (2013). A Service Science Perspective on Business Model Innovation. Industrial marketing Management, 42(5), 665-670. https://doi.org/10.1016/j.indmarman.2013.05.007

O'Cass, A., \& Ngo, L. (2011). Examining the Firm's Value Creation Process: A Managerial Perspective of the Firm's Value Offering Strategy and Performance. British Journal of Management, 22(4), 646-671. https://doi.org/10.1111/j.1467-8551.2010.00694.x

Okdinawati, L., Simatupang, T.M., \& Sunitiyoso, Y. (2015). Modelling Collaborative Transportation Management: Current State and Opportunities for Future Research. Journal of Operations and Supply Chain Management, 8(2), 96-119. https://doi.org/10.12660/joscmv8n2p96-119 
Pandey, P., Khumar, S., \& Pandey, D. (2010). Reinforcement Learning by Comparing Immediate Reward. International Journal of Computer Science and Information Security, 8(5).

Prahalad, C., \& Ramaswamy, V. (2004). Co creation Experiences: The Next practice in Value Creation. Journal of Interactive Marketing, 18(3), 5-14. https://doi.org/10.1002/dir.20015

Ramirez, R. (1999). Value Co-production: Intellectual Origins and Implications for Practice and Research. Strategic Management Journal, 20(1), 49-65. https://doi.org/10.1002/(SICI)1097-0266(199901)20:1<49::AIDSMJ20>3.0.CO;2-2

Ritter, T., \& Walter, A. (2012). More is not always better: The impact of relationship functions on customer-perceived relationship value. Industrial Marketing Management, 41(1), 136-144. https://doi.org/10.1016/j.indmarman.2011.11.020

Sanders, L., \& Simons, G. (2009). A Social Vision for Value Co-Creation In Design. Open Source Business Resource.

Sebastiani, R., Corsaro, D., \& Vargo, S.L. (2014). Transitioning to value co-development. In Managing Consumer Services, 131-149. https://doi.org/10.1007/978-3-319-04289-3_8

Smith, J.B., \& Colgate, M. (2007). Customer Value Creation: A Practical Framework. Journal of Marketing Theory and Practice, 15(1), 7-23. https://doi.org/10.2753/MTP1069-6679150101

Stewart, R.B., \& Ebrary, I. (2010). Value Optimization for Project and Performance Management. Hoboken, N.J.: Wiley.

Storbacka, K., Frow, P., Nenonen, S., \& Payne, A. (2012). Designing Business Models for Value Co-creation. In Special Issue-Toward a Better Understanding of the Role of Value in Markets and Marketing, 51-78. https://doi.org/10.1108/S1548-6435(2012)0000009007

Sutherland, J.L. (2003). Collaborative Transportation Management-Creating Value Trough Increased Transportation Efficiencies. Business Briefing - Pharmagenerics, 1-4.

The Jakarta Post (2011). Enseval Eyes 20\% Rise in Revenue, Profit. Available online at: http://www.thejakartapost.com/news (Accessed: November 2015).

Vargo, S.L., \& Lusch, R.F. (2008). Service-dominant Logic: Continuing the Evolution. Journal of the Academy of Marketing Science, 36(1), 1-10. https://doi.org/10.1007/s11747-007-0069-6

Vargo, S.L., \& Lusch, R.F. (2011). It's All B2B ... and Beyond: Toward a Systems Perspective of The Market. Industrial Marketing Management, 40(2), 181-187. https://doi.org/10.1016/j.indmarman.2010.06.026 
VICS (CTM sub-committee of the Voluntary Inter-Industry Commerce Standards Logistic Committee) (2004). Collaborative Transportation Management White Paper Version 1.0. http://www.vics.org (Accessed: October 2013).

Voima, P., Heinonen, K., \& Strandvik, T. (2010). Exploring Customer Value Formation-a Customer Dominant Logic Perspective. Working paper No. 552. Publications of Hanken School of Economics, Helsinki, Finland.

Watkins, C.J.C.H., \& Dayan, P. (1992). Q-learning. Machine learning, 8(3-4), 279-292. https://doi.org/10.1007/BF00992698

Journal of Industrial Engineering and Management, 2017 (www.jiem.org)

(ब)

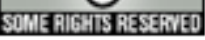

Article's contents are provided on an Attribution-Non Commercial 3.0 Creative commons license. Readers are allowed to copy, distribute and communicate article's contents, provided the author's and Journal of Industrial Engineering and Management's names are included. It must not be used for commercial purposes. To see the complete license contents, please visit http://creativecommons.org/licenses/by-nc/3.0/. 